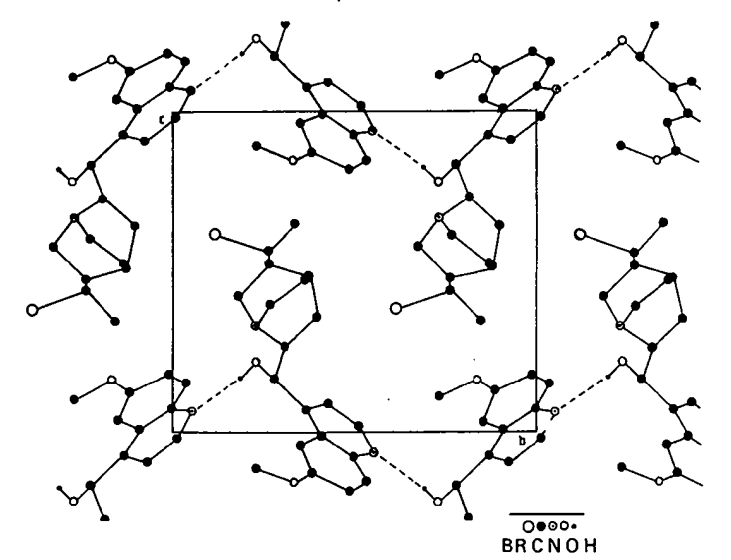

Fig. 2. Projection of the structure along a. The hydrogen bonds are indicated by broken lines. The $\mathbf{H}$ atoms are omitted except that belonging to the hydroxyl group.

The $\mathrm{C}-\mathrm{Br}$ distance $[1.988(6) \AA]$ is typical of $\mathrm{C}_{s p^{3}}-\mathrm{Br}$ bonds in similar substructures (Allen, Kennard, Watson, Brammer, Orpen \& Taylor, 1987).

The least-squares plane of the quinoline ring shows that the largest deviation from the plane is $0.072(6) \AA$ for the $\mathrm{C}(26)$ atom connected to the $\mathrm{O}$ atom of the methoxy group; the methoxy $\mathrm{O}(2)$ and C(31) atoms are located at $0 \cdot 188(5)$ and 0.359 (9) $\AA$ from this plane.

Packing of the molecules and the hydrogenbonding scheme is shown in Fig. 2. Molecules related by $2_{1}$ axes are linked together by hydrogen bonds between $\mathrm{O}(1)$ of the hydroxyl group and $N(2)$ of the quinoline ring with the distances: $O\left(1^{\mathrm{i}}\right) \cdots \mathrm{N}\left(2^{\mathrm{ii}}\right)$ $2 \cdot 844(7), \quad \mathrm{H}\left(\mathrm{O} 1^{\mathrm{i}}\right) \cdots \mathrm{N}\left(2^{\mathrm{ii}}\right) 2 \cdot 14(5) \AA$ and the angle $\mathrm{O}\left(1^{\mathrm{i}}\right)-\mathrm{H}\left(\mathrm{O} 1^{\mathrm{i}}\right) \cdots \mathrm{N}\left(2^{\mathrm{ii}}\right) 174(6)^{\circ}$, where (i) $=x, y, z$ and (ii) $=-x, y-1 / 2,-z$. In other Cinchona alkaloids and their derivatives hydrogen bonds are formed either by the more basic $N(1)$ quinuclidine $N$ atom or by both $\mathrm{N}(1)$ and $\mathrm{N}(2)$ quinuclidine and quinoline $\mathrm{N}$ atoms.

Measurements of the intensities were carried out at the Institute of Physical Chemistry, Polish Academy of Sciences, Warsaw. This research was supported by Project RP.II.10 from the Polish Ministry of Education.

\section{References}

Allen, F. H., Kennard, O., Watson, D. G., Brammer, L., OrPen, A. G. \& TAYLOR, R. (1987). J. Chem. Soc. Perkin Trans. 2, pp. S1-S19.

Carter, O. L., McPhail, A. T. \& Sim, G. A. (1967). J. Chem. Soc. $A, 365-373$.

Doherty, R., Benson, W. R., Maienthal, M. \& Stewart, J. MCD. (1978). J. Pharm. Sci. 67, 1698-1701.

Karle, I. L. \& Karle, J. (1981). Proc. Natl Acad. Sci. USA, 78, 5938-5941.

Kashino, A. \& Haisa, M. (1983). Acta Cryst. C39, 310-312.

Main, P., Fiske, S. J., Hull, S. E., Lessinger, L., Germain, G., DeClerCQ, J. P. \& WoOlfson, M. M. (1980). MULTAN80. A System of Computer Programs for the Automatic Solution of Crystal Structures from X-ray Diffraction Data. Univs. of York, England, and Louvain, Belgium.

Motherwell, W. D. S. \& ClegG, W. (1978). PLUTO. Program for plotting molecular and crystal structures. Univ. of Cambridge, England.

NARDELli, M. (1983). Comput. Chem. 7, 95-98.

Rogers, D. (1981). Acta Cryst. A37, 734-741.

SheldrICK, G. M. (1976). SHELX76. Program for crystal structure determination. Univ. of Cambridge, England.

Suszko-PurzycKA, A., LiPÍ́sKa, T., KarCZMARzYK, Z. \& PNIEWSKA, B. (1987). J. Crystallogr. Spectrosc. Res. 17, 31-40.

TURner, R. B. \& Woodward, R. B. (1953). The Alkaloids, Vol. III, edited by R. H. F. MANSKe \& H. L. Holmes, pp. 1-63. New York: Academic Press.

Acta Cryst. (1990). C46, 2126-2128

\title{
Structure of 1,4-Bis(3-quinolyl)-1,3-butadiyne
}

\author{
By Kalyan Das and U. C. Sinha* \\ Department of Physics, Indian Institute of Technology, Bombay-40076, India
}

S. S. TAlWAR AND M. B. Kamath

Department of Chemistry, Indian Institute of Technology, Bombay-400076, India

AND RAKESH BOHRA

Department of Chemistry, University of Rajasthan, Jaipur-302016, India

(Received 31 May 1989; accepted 10 January 1990)
Abstract. $\mathrm{C}_{22} \mathrm{H}_{12} \mathrm{~N}_{2}, M_{r}=304 \cdot 47$, monoclinic, $P 2_{1} / c$, $a=4.807$ (3), $b=13.687$ (4), $c=11.909$ (2) $\AA, \beta=$
$95.34(3)^{\circ}, \quad V=780.59 \AA^{3}, \quad Z=2, \quad D_{x}=$

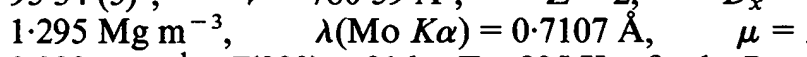 $0.083 \mathrm{~mm}^{-1}, \quad F(000)=316, T=295 \mathrm{~K}$, final $R=$
* To whom correspondence should be addressed. 0.0636 for 528 reflections with $F>5.0 \sigma(|F|)$. The 0108-2701/90/112126-03\$03.00 (C) 1990 International Union of Crystallography 
monomer structure satisfies the topochemical polymerization conditions [Wegner (1977). Chemistry and Physics of One-Dimensional Metals, edited by H. J. Keller, pp. 297-314. New York: Plenum] with $D=$ $3.603(8), \quad S_{1}=3.450(8) \AA$ and the angle $\gamma_{1}=$ $47 \cdot 5(6)^{\circ}$.

Introduction. Many diacetylenes (having the general formula $R-\mathrm{C} \equiv \mathrm{C}-\mathrm{C} \equiv \mathrm{C}-R$ ) undergo solid-state polymerization reactions (Wegner, 1969) by thermal, mechanical or photochemical stimulation. The reaction proceeds by 1,4 addition to form a highly conjugated polymer.
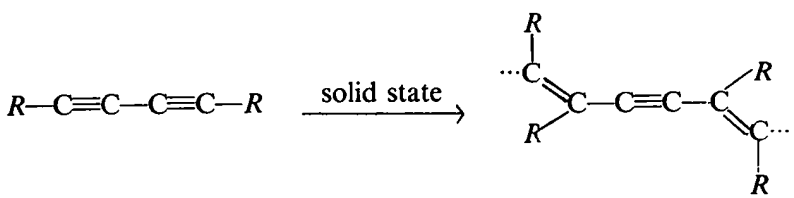

Suitable molecular packing conditions (Baughman, 1974; Wegner, 1977; Bloor, 1982) are necessary to observe reactivity in the lattice.

An X-ray crystal structure determination of the title compound, in which the substituted $R$ group is in formal $\pi$ conjugation with the diacetylene group, has been undertaken to correlate the reactivity of the diacetylene crystals in the polymerization reaction.

Experimental. The title compound, 1,4-bis(3quinolyl)-1,3-butadiyne (DQ), was synthesized by the coupling of 3-ethynylquinoline (Amis, Bull \& Takundwar, 1981) using the method of Fritzche \& Hunig (1972). DQ crystallized from acetone as almost colourless needles which quickly turned blue in ambient conditions owing to a small amount of polymerization $(<1 \%)$.

A blue crystal of dimensions $0.075 \times 0.075 \times$ $0.40 \mathrm{~mm}$ was selected for X-ray intensity-data collection using an Enraf-Nonius CAD-4 diffractometer with graphite-monochromated Mo $K \alpha$ radiation. The space group and lattice parameters were determined from double-oscillation and Weissenberg photographs. The lattice parameters were refined on setting angles of 25 reflections in the range $4.5 \leq \theta \leq$ $12^{\circ}$. The intensities of 1612 unique reflections were measured $(\omega / 2 \theta$ scan $)$ in the range of $2 \leq \theta \leq 25^{\circ}$ (resolution $d=0.84$ ), $0 \leq h \leq 5,0 \leq k \leq 16,-14 \leq l$ $\leq 14$. Two standard reflections $(1 \overline{3} \overline{3}$ and $1 \overline{3} \overline{5})$ measured every 1800 s indicated no intensity decay. Lp corrections but no abosorption corrections were applied. Because the crystal dimensions were small, only 934 observed reflections were obtained $[F>$ $3 \cdot 0 \sigma(|F|)]$ and used for structure determination. The structure was solved by direct methods using $S H E L X S 86$ (Sheldrick, 1985) with $R_{E}=0 \cdot 192$. The structure was refined by least-squares methods based
Table 1. Atomic coordinates $\left(\times 10^{4}\right)$ and equivalent isotropic temperature factors $U_{\mathrm{eq}}\left(\AA^{2} \times 10^{3}\right)$ for non- $\mathrm{H}$ atoms with e.s.d.'s in parentheses

\begin{tabular}{|c|c|c|c|}
\hline$x$ & $y$ & $z$ & $U_{\text {eq }}$ \\
\hline 883 (13) & 4707 (4) & $9731(5)$ & $43(4)$ \\
\hline 2449 (13) & $4193(5)$ & $9284(5)$ & $45(4)$ \\
\hline 4409 (12) & 3584 (4) & 8761 (5) & $39(4)$ \\
\hline 4962 (14) & 3805 (5) & $7638(6)$ & $47(4)$ \\
\hline 6758 (11) & 3305 (4) & $7083(4)$ & $45(4)$ \\
\hline 8053 (13) & $2518(5)$ & $7622(6)$ & $45(4)$ \\
\hline 9981 (14) & $1984(5)$ & 7040 (5) & 49 (4) \\
\hline 11273 (14) & $1204(5)$ & $7536(6)$ & $55(4)$ \\
\hline 10784 (14) & 899 (5) & $8635(6)$ & $58(4)$ \\
\hline 8958 (14) & $1419(5)$ & 9203 (6) & 57 (4) \\
\hline $7564(13)$ & $2246(4)$ & $8725(5)$ & $41(4)$ \\
\hline $5625(12)$ & $2799(5)$ & $9294(5)$ & $41(4)$ \\
\hline
\end{tabular}

Table 2. Bond distances $(\AA)$ and angles $\left(^{\circ}\right)$ with e.s.d.'s in parentheses

\begin{tabular}{|c|c|c|c|}
\hline$C(2)-C(1)$ & $1 \cdot 192(7)$ & $C(10)-C(5)$ & $1.406(8)$ \\
\hline$C(3)-C(2)$ & $1.442(8)$ & $C(7)-C(6)$ & $1 \cdot 344(8)$ \\
\hline$C(4)-C(3)$ & $1.421(8)$ & $C(8)-C(7)$ & $1.414(9)$ \\
\hline$C(11)-C(3)$ & $1.353(8)$ & $\mathrm{C}(9)-\mathrm{C}(8)$ & $1.359(8)$ \\
\hline $\mathrm{N}-\mathrm{C}(4)$ & $1.325(7)$ & $C(10)-C(9)$ & $1.408(8)$ \\
\hline$C(5)-N$ & $1.373(7)$ & $C(11)-C(10)$ & $1.421(8)$ \\
\hline$C(6)-C(5)$ & $1.412(8)$ & $C(1)-C\left(1^{\prime}\right)$ & 1.369 (11) \\
\hline$C(3)-C(2)-C(1)$ & $178 \cdot 4(6)$ & $C(7)-C(6)-C(5)$ & $119 \cdot 5(6)$ \\
\hline$C(4)-C(3)-C(2)$ & $118.0(6)$ & $C(8)-C(7)-C(6)$ & $122 \cdot 2(6)$ \\
\hline$C(11)-C(3)-C(2)$ & $121.9(6)$ & $\mathrm{C}(9)-\mathrm{C}(8)-\mathrm{C}(7)$ & $118.4(6)$ \\
\hline$C(11)-C(3)-C(4)$ & $120 \cdot 1(6)$ & $C(10)-C(9)-C(8)$ & $121.7(6)$ \\
\hline $\mathrm{N}-\mathrm{C}(4)-\mathrm{C}(3)$ & $123 \cdot 2(6)$ & $\mathrm{C}(9)-\mathrm{C}(10)-\mathrm{C}(5)$ & $118.4(6)$ \\
\hline$C(5)-N-C(4)$ & $117 \cdot 4(6)$ & $C(11)-C(10)-C(5)$ & $118 \cdot 6(6)$ \\
\hline$C(6)-C(5)-N$ & $117.8(6)$ & $C(11)-C(10)-C(9)$ & $122.9(6)$ \\
\hline$C(10)-C(5)-N$ & $122 \cdot 4(6)$ & $C(10)-C(11)-C(3)$ & $118 \cdot 2(6)$ \\
\hline$C(10)-C(5)-C(6)$ & $119 \cdot 7(6)$ & & \\
\hline
\end{tabular}

on $F$ values using SHELX76 (Sheldrick, 1976). The atomic scattering factors for all the atoms were from SHELX76. All the non-H atoms were refined with anisotropic thermal parameters and the $\mathrm{H}$ atoms with isotropic thermal parameters. The final $R=$ 0.0636 and $w R=0.058$ \{where $w=k /\left[\sigma^{2}\left(F_{o}\right)+\right.$ $\left.g\left(F_{o}\right)^{2}\right]$ with $k=2.4811$ and $\left.g=0.00\right\}$ for 528 reflections with $F \geq 5 \sigma|F|,(\Delta / \sigma)_{\max }=0.085$. In the final difference Fourier map, $(\Delta \rho)_{\max }=0.224$ and $(\Delta \rho)_{\min }$ $=-0.263 \mathrm{e} \AA^{-3}$. A CYBER-180 was used for all the computations.

Discussion. Table $1^{*}$ gives the atomic coordinates and equivalent isotropic temperature factors of the non- $\mathrm{H}$ atoms in an asymmetric unit. The bond lengths and angles are given in Table 2. Fig. 1 shows the PLUTO78 (Motherwell \& Clegg, 1978) diagram of the monomer molecule.

\footnotetext{
* Lists of structure factors, anisotropic thermal parameters and $\mathrm{H}$-atom parameters have been deposited with the British Library Document Supply Centre as Supplementary Publication No. SUP 52952 (6 pp.). Copies may be obtained through The Technical Editor, International Union of Crystallography, 5 Abbey Square, Chester CH1 2HU, England.
} 
The bond distances in the diacetylene chain are $\mathrm{C}(1)-\mathrm{C}(1)^{\prime} 1 \cdot 369(11)$ and $\mathrm{C}(1) \equiv \mathrm{C}(2) 1 \cdot 192(7) \AA$ compared with the respective values 1.39 (3) and $1 \cdot 18(3) \AA$ reported for 1,4-diphenyl-1,3-butadiyne (Wiebenga, 1940) and 1.379 (4) and 1.192(3) $\AA$ for 1,4-bis(2-pyridyl)-1,3-butadiyne (Swaminathan, Sinha, Kamath, Talwar \& Bohra, 1989). The $\mathrm{C}(1)^{\prime}-\mathrm{C}(1)-\mathrm{C}(2)$ bond is almost linear $\left[C(1)^{\prime}-C(1)-C(2)=178 \cdot 7(7)^{\circ}\right]$. Fig. 2 represents the stereo packing of the molecules. The intermolecular distances confirm that only van der Waals interactions are present between adjacent molecules. The aromatic groups, attached to diacetylene rods, are almost parallel to each other. The observed bond lengths (Table 2) in the aromatic rings of the

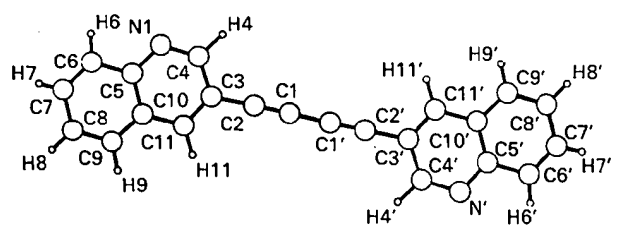

Fig. 1. PLUTO drawing of the monomer molecule.
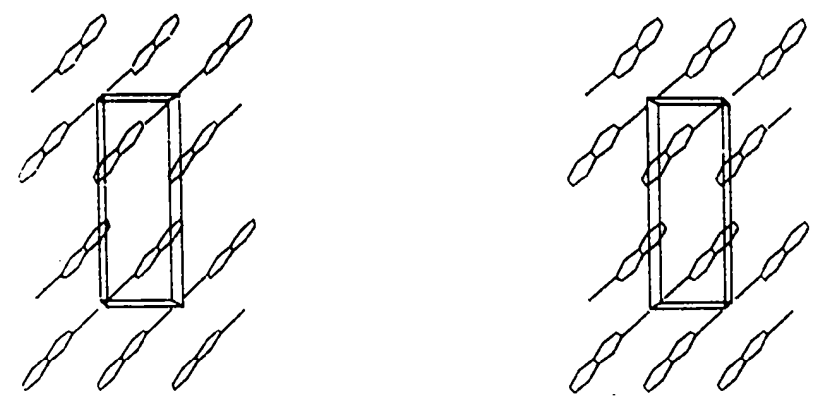

Fig. 2. Stereoview of the packing of the molecules.

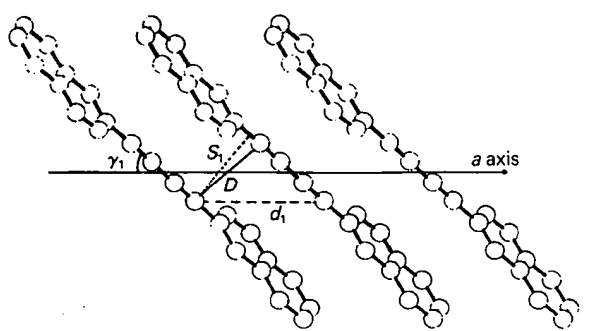

Fig. 3. Monomer packing requirements with limits $3 \cdot 4<S_{1}<$ $4.0 \AA$ and $\gamma_{1} \simeq 45^{\circ}$. quinolyl group are very close to those reported for a substituted quinoline (Harlow, Simonsen \& Sammes, 1976) and those obtained by SCF LCAO-MO or SCF-MO (Hückel approximations) (Dewar \& Gleicher, 1966) calculations for quinoline. This suggests that neither the resonance structures of the aromatic rings nor the conjugation with the diacetylene group significantly affects the electron density distribution.

The necessary monomer packing conditions (Wegner, 1977; Bloor, 1982) required for the solidstate polymerization reaction (given in square brackets) are well satisfied in case of DQ (Fig. 3) as mentioned below.

(i) The distance between $\mathrm{C}(2)$ and $\mathrm{C}(2)^{\prime}$ of adjacent molecules is 3.603 (8) $\AA[D<4.0 \AA]$.

(ii) The separation between the successive diacetylene molecules along the axis of polymerization (i.e. the $a$ axis) is $d_{1}(\equiv \mathrm{a})=4.807$ (3) $\AA$.

(iii) $\gamma_{1}=47 \cdot 5(6)^{\circ}\left[\gamma_{1} \simeq 45^{\circ}\right]$.

(iv) $S_{1}=d_{1} \sin \left(\gamma_{1}\right), \quad S_{1}=3.450$ (8) $\AA \quad\left[3.4 \leq S_{1} \leq\right.$ $4.0 \AA]$.

It is worth noting that despite very favourable molecular packing, the maximum polymerization observed was only around $25 \%$. Detailed crystal structure studies of the partially polymerized crystal and the crystalline polymer, obtained after the extraction of the monomer, have not been successful so far because the crystals obtained are too thin to diffract X-rays properly. Attempts to grow suitable polymer crystals are in progress.

\section{References}

Amis, D. E., Bull, D. \& TaKundwar, C. (1981). Synthesis, pp. 364-365.

Baughman, R. H. (1974). J. Polym. Sci. 12, 1511-1535.

Bloor, D. (1982). Developments in Crystalline Polymers, edited by D. C. BassetT, Vol. 1, p. 151. London: Applied Science Publishers.

Dewar, M. J. S. \& Gleicher, G. J. (1966). J. Chem. Phys. 44, 759-773.

FritzChE, U. \& HuNIG, S. (1972). Tetrahedron Lett. 47, 48314834.

Harlow, R. L., Simonsen, S. H. \& Sammes, M. P. (1976) Acta Cryst. B32, 2690-2693.

Motherwell, W. D. S. \& ClegG, W. (1978). PLUTO. Program for plotting molecular and crystal structures. Univ. of Cambridge, England.

SHELDRICK, G. M. (1976). SHELX76. Program for crystal structure determination. Univ. of Cambridge, England.

SHELDRICK, G. M. (1985), SHELXS86. In Crystallographic Computing 3, edited by G. M. SHELdRICK, C. KRÜGER \& R. GodDard, pp. 175-189. Oxford Univ. Press.

Swaminathan, K., Sinha, U. C., Kamath, M. B., Talwar, S. S. \& BoHRA, R. (1989). Acta Cryst. C45, 504-506.

WEGNER, G. (1969). Z. Naturforsch Teil B, 24, 824-832.

Wegner, G. (1977). Chemistry and Physics of One-Dimensional Metals, edited by H. J. KelleR, pp. 297-314. New York: Plenum.

WIEBENGA, E. H. (1940). Z. Kristallogr. 102, 193-206. 